Buletin Ilmiah Mat. Stat. dan Terapannya (Bimaster)

Volume 08, No. 2 (2019), hal 221-228.

\title{
PENERAPAN ANALISIS FOURIER UNTUK MENENTUKAN PERIODE DAN PREDIKSI SUHU UDARA (Studi Kasus: Data Suhu Udara Kota Pontianak)
}

\author{
Maulydiana Septiani, Helmi, Yudhi
}

INTISARI

\begin{abstract}
Suhu udara merupakan salah satu unsur iklim yang penting untuk diamati. Perubahan pada suhu udara memiliki berbagai dampak terhadap kehidupan masyarakat di bidang pertanian, transportasi dan sebagainya. Suhu udara dapat diprediksi dengan menggunakan metode aproksimasi Deret Fourier. Persamaan aproksimasi Deret Fourier membutuhkan periode sebagai salah satu variabel dan metode yang dapat digunakan untuk mencari periode yaitu Transformasi Fourier Cepat. Hasil penelitian yang diperoleh yaitu periode suhu udara di Kota Pontianak tahun 2008 sampai dengan 2017 sebesar 12 bulan. Hasil penelitian tersebut menunjukkan bahwa kenaikan dan penurunan suhu udara berulang setiap 12 bulanan. Hasil prediksi suhu udara dengan aproksimasi Deret Fourier berorde enam pada tahun 2018 yaitu suhu udara maksimum mencapai $37,025^{\circ} \mathrm{C}$. Berdasarkan Peraturan Kepala Badan Meteorologi, Klimatologi dan Geofisika Nomor Keputusan 009 Tahun 2010 mengenai definisi suhu udara ekstrim, maka hasil prediksi tersebut menunjukkan bahwa suhu udara di Kota Pontianak tidak ekstrim atau masih dalam kondisi normal.
\end{abstract}

Kata Kunci: Aproksimasi, Deret Fourier, Transformasi Fourier.

\section{PENDAHULUAN}

Indonesia termasuk negara beriklim tropis sehingga wilayah ini memiliki curah hujan yang cukup tinggi. Indonesia hanya memiliki dua musim, yaitu kemarau dan hujan [1]. Suhu udara merupakan salah satu unsur iklim yang perlu diamati. Kota Pontianak mengalami perubahan pada suhu udara. Perubahan pada suhu udara akan memiliki dampak terhadap berbagai bidang kehidupan di masyarakat seperti pertanian, arsitektur, transportasi dan lain sebagainya.

Prediksi mengenai suhu udara sangat penting untuk menghindari terjadinya dampak akibat perubahan suhu udara. Metode analisis Fourier yang dapat digunakan dalam memprediksi suhu udara yaitu pendekatan atau aproksimasi Deret Fourier. Telah dilakukan penelitian mengenai prediksi pergerakan suhu udara. Periode suhu udara pada penelitian tersebut diasumsikan sama, sedangkan periode pada suatu waktu maupun tempat dapat berbeda [2]. Analisis Fourier yang dapat digunakan untuk mencari periode yaitu Transformasi Fourier Cepat. Transformasi Fourier Cepat dapat mengubah data dari daerah waktu pada Deret Fourier menjadi daerah frekuensi sehingga dapat ditentukan periode yang merupakan kebalikan dari frekuensi. Tujuan dari penelitian ini adalah menerapkan analisis Fourier untuk menentukan periode dan prediksi suhu udara.

Langkah awal dalam penelitian ini yaitu menentukan nilai $N$ dan $M$ pada persamaan Transformasi Fourier Cepat berdasarkan data suhu udara di Kota Pontianak. $N$ yaitu jumlah seluruh data dan $M$ yaitu setengah dari jumlah seluruh data. Setelah diperoleh nilai $N$ dan $M$, selanjutnya mencari nilai bobot pada $N$ dan $M$. Nilai bobot $N$ dan $M$ digunakan untuk mencari fungsi genap dan fungsi ganjil pada Transformasi Fourier Cepat. Langkah dilanjutkan dengan mencari frekuensi pada Transformasi Fourier Cepat. Frekuensi adalah kebalikan dari periode. Periode yang telah diperoleh selanjutnya disubstitusikan dengan data suhu udara untuk mencari koefisien-koefisien dari setiap orde. Setelah itu, substitusikan koefisien untuk mencari aproksimasi pada setiap orde. Langkah selanjutnya yaitu mengidentifikasi orde yang paling mendekati aproksimasi. Orde tersebut digunakan untuk mencari prediksi pada aproksimasi Deret Fourier. 


\section{DERET FOURIER}

Suatu fungsi periodik sebarang dapat dinyatakan dalam bentuk sinusoid tak hingga yang frekuensifrekuensinya berkaitan secara harmonis. Fungsi periodik $f(t)$ adalah fungsi yang memenuhi $f(t)=$ $f(t+T)$ dengan $T$ adalah periode yang berupa konstanta [3]. Joseph Fourier mengemukakan bahwa sebuah fungsi periodik dapat direpresentasikan dengan mengkombinasikan penjumlahan tak hingga dari fungsi sinus dan cosinus. Representasi fungsi inilah yang dikenal sebagai Deret Fourier [4]. Deret Fourier kontinu dapat dituliskan sebagai berikut untuk fungsi $f(t)$ dengan periode $T$ [3]:

$$
f(t)=a_{0}+a_{1} \cos (\omega t)+b_{1} \sin (\omega t)+a_{2} \cos (2 \omega t)+b_{2} \sin (2 \omega t)+\ldots
$$

atau dapat disederhanakan menjadi

$$
f(t)=a_{0}+\sum_{k=1}^{\infty}\left[a_{k} \cos (k \omega t)+b_{k} \sin (k \omega t)\right]
$$

dengan $\omega=\frac{2 \pi}{T}$ adalah frekuensi sedangkan $a_{0}, a_{k}$ dan $b_{k}$ adalah koefisien.

Koefisien-koefisien dari Persamaan (1) dapat dituliskan sebagai berikut:

$$
\begin{aligned}
& a_{0}=\frac{1}{T} \int_{0}^{T} f(t) d t \\
& a_{k}=\frac{2}{T} \int_{0}^{T} f(t) \cos (k \omega t) d t \\
& b_{k}=\frac{2}{T} \int_{0}^{T} f(t) \sin (k \omega t) d t
\end{aligned}
$$

\section{TRANSFORMASI FOURIER}

Deret Fourier dapat dikembangkan ke bentuk yang lebih umum, kemudian dikenal dengan Transformasi Fourier. Berdasarkan persamaan Euler $e^{ \pm i x}=\cos x \pm i \sin x$, maka bentuk sinus dan cosinus dapat dinyatakan dalam bentuk eksponen sebagai berikut [3] :

$$
\cos (k \omega t)=\frac{e^{i k \omega t}+e^{-i k \omega t}}{2}
$$

$$
\sin (k \omega t)=\frac{e^{i k \omega t}-e^{-i k \omega t}}{2 i}
$$

Substitusikan Persamaan (5) dan (6) ke Persamaan (1) sehingga diperoleh :

$$
f(t)=a_{0}+\sum_{k=1}^{\infty}\left[e^{i k \omega t}\left(\frac{a_{k}-i b_{k}}{2}\right)+e^{-i k \omega t}\left(\frac{a_{k}+i b_{k}}{2}\right)\right]
$$

Dikarenakan fungsi ganjil dan genap pada bentuk sinus dan cosinus maka dapat dibentuk persamaan sebagai berikut:

$$
\tilde{c}_{0}=a_{0}
$$$$
\tilde{c}_{k}=
$$$$
\frac{a_{k}-i b_{k}}{2}
$$

$$
\begin{aligned}
\tilde{c}_{-k} & =\frac{a_{-k}-i b_{-k}}{2} \\
& =\frac{a_{k}+i b_{k}}{2}
\end{aligned}
$$

Substitusikan Persamaan (8) sampai dengan (10) ke Persamaan (7) sehingga diperoleh sebagai berikut:

$$
f(t)=\sum_{k=-\infty}^{\infty} \tilde{c}_{k} e^{i k \omega t}
$$

Substitusikan Persamaan (3) dan (4) ke Persamaan (9) sehingga diperoleh sebagai berikut:

$$
\tilde{c}_{k}=\frac{1}{T} \int_{-T / 2}^{T / 2} f(t) e^{-i k \omega t} d t
$$

untuk $T \rightarrow \infty$ dapat dinyatakan persamaan sebagai berikut: 


$$
\tilde{c}_{k} T=\int_{-\infty}^{\infty} f(t) e^{-i k \omega t} d t
$$

Dimisalkan $\tilde{c}_{k} T=F(\omega)$ selanjutnya substitusikan ke Persamaan (12) sehingga diperoleh persamaan sebagai berikut:

$$
F(\omega)=\int_{-\infty}^{\infty} f(t) e^{-i \omega t} d t
$$

$F(\omega)$ disebut sebagai Transformasi Fourier.Substitusikan Persamaan (14) ke Persamaan (12) dengan $T \rightarrow \infty$ sehingga dapat diperoleh sebagai berikut:

$$
\tilde{c}_{k}=\frac{1}{T} F(\omega)
$$

Selanjutnya dicari invers dari Transformasi Fourier $F(\omega)$ berupa fungsi kontinu bagian demi bagian dengan mensubstitusikan Persamaan (15) ke Persamaan (11) sebagai berikut:

$$
f(t)=\frac{1}{2 \pi} \int_{-\infty}^{\infty} F(\omega) e^{i \omega t} d \omega
$$

$f(t)$ adalah invers dari Transformasi Fourier $F(\omega)$.

Transformasi Fourier dapat dinyatakan dalam bentuk diskrit. Selang pada Transformasi Fourier dapat dibagi menjadi $N$ selang yang berjarak sama, maka dapat dibentuk Transformasi Fourier Diskrit sebagai berikut [3]:

$$
F_{k}=\sum_{n=0}^{N-1} f_{n} e^{-i k \omega n}
$$

dengan $f_{n}$ adalah suatu nilai dari fungsi kontinu $f(t)$ diambil pada $t_{n}$ dan $n=0,1,2 \ldots, N-1$ Sedangkan untuk invers dari Transformasi Fourier Diskrit dapat dibentuk sebagai berikut:

$$
f_{n}=\frac{1}{N} \sum_{k=0}^{N-1} F_{k} e^{i k \omega n}
$$

\section{KRITERIA PENGUKURAN KETEPATAN MAPE DAN MSE}

Metode-metode peramalan seperti Transformasi Fourier Cepat dan aproksimasi Deret Fourier memiliki ukuran ketepatan. Ukuran ketepatan yang dapat digunakan yaitu Mean Squared Error (MSE) dan Mean Absolute Percentage Error (MAPE).

Mean Squared Error (MSE) adalah kesalahan nilai tengah kuadrat. Cara menghitung Mean Squared Error (MSE) yaitu menjumlahkan kuadrat kesalahan kemudian membaginya dengan banyaknya data. Bentuk perhitungan Mean Squared Error (MSE) adalah sebagai berikut [5] :

$$
\operatorname{MSE}=\frac{1}{n} \sum_{t=1}^{n}(S(t)-\hat{S}(t))^{2}
$$

dengan $n$ adalah banyaknya data, $S(t)$ adalah data aktual ke- $t$ dan $\hat{S}(t)$ adalah data prediksi ke- $t$.

Mean Absolute Percentage Error (MAPE) adalah kesalahan nilai tengah persentase absolut. Bentuk perhitungan Mean Absolute Percentage Error (MAPE) adalah sebagai berikut [5] :

$$
\text { MAPE }=\frac{1}{n} \sum_{t=1}^{n}\left|\frac{S(t)-\hat{S}(t)}{S(t)}\right| \times 100 \%
$$

dengan $n$ adalah banyaknya data, $S(t)$ adalah data aktual ke- $t$ dan $\hat{S}(t)$ adalah data prediksi ke- $t$.

Suatu persamaan memiliki kemampuan peramalan sangat baik jika nilai MAPE berada dibawah 10\% dan memiliki kemampuan peramalan baik jika nilai MAPE berada diantara 10\% dan 20\% [6].

\section{TRANSFORMASI FOURIER CEPAT PADA SUHU UDARA}

Transformasi Fourier Cepat adalah algoritma pengembangan dari Transformasi Fourier Diskrit. Berdasarkan Persamaan (17) Transformasi Fourier Diskrit dapat dinyatakan sebagai berikut:

$$
F_{k}=\sum_{n=0}^{N-1} f_{n} W_{N}^{n k} \text { dengan } W_{N}=e^{-i\left(\frac{2 \pi}{N}\right)}
$$

Dimisalkan $M=\frac{N}{2}$ dan $N$ bernilai genap. Persamaan (19) terbagi menjadi dua bagian yaitu untuk nilai $n$ genap dan $n$ ganjil sebagai berikut:

$$
\begin{aligned}
F_{k} & =\sum_{n=0}^{M-1} f_{2 n} e^{-i\left(\frac{2 \pi}{N}\right) 2 n k}+\sum_{n=0}^{M-1} f_{(2 n+1)} e^{-i\left(\frac{2 \pi}{N}\right)(2 n+1) k} \\
& =\sum_{n=0}^{M-1} f_{2 n} W_{N}{ }^{2 n k}+\sum_{n=0}^{M-1} f_{(2 n+1)} W_{N}{ }^{2 n k} W_{N}{ }^{k}
\end{aligned}
$$




$$
\begin{aligned}
& =\sum_{n=0}^{M-1} f_{2 n} W_{N}{ }^{2 n k}+W_{N}{ }^{k} \sum_{n=0}^{M-1} f_{(2 n+1)} W_{N}{ }^{2 n k} \\
& =\sum_{n=0}^{M-1} f_{2 n} W_{M}{ }^{n k}+W_{N}{ }^{k} \sum_{n=0}^{M-1} f_{(2 n+1)} W_{M}{ }^{n k}
\end{aligned}
$$

dengan $W_{M}^{n k}=e^{-i\left(\frac{2 \pi}{N}\right) 2 n k}=e^{-i\left(\frac{2 \pi}{N / 2}\right) n k}$

Selanjutnya untuk mencari $F_{k+M}$, substitusikan $k+M$ ke Persamaan (20) sehingga diperoleh sebagai berikut:

$$
\begin{aligned}
F_{k+M} & =\sum_{n=0}^{M-1} f_{2 n} W_{M}{ }^{n(k+M)}+W_{N}{ }^{(k+M)} \sum_{n=0}^{M-1} f_{(2 n+1)} W_{M}{ }^{n(k+M)} \\
& =\sum_{n=0}^{M-1} f_{2 n} W_{M}{ }^{n k} W_{M}{ }^{n M}+W_{N}{ }^{k} W_{N}{ }^{M} \sum_{n=0}^{M-1} f_{(2 n+1)} W_{M}{ }^{n k} W_{M}{ }^{n M} \\
& =\sum_{n=0}^{M-1} f_{2 n} W_{M}{ }^{n k}-W_{N}{ }^{k} \sum_{n=0}^{M-1} f_{(2 n+1)} W_{M}{ }^{n k}
\end{aligned}
$$

Karena $W_{N}{ }^{M}=e^{-i 2 \pi M / N}=e^{-i \pi}=-1$ dan $W_{M}{ }^{n M}=e^{-i 2 \pi n M / M}=e^{-2 i \pi n}=1$

Setelah diperoleh $F_{k}$ dan $F_{k+M}$, selanjutnya mencari periode yang ditentukan menggunakan 120 data dari tahun 2008 sampai dengan 2017. Data tersebut dapat dibentuk ke persamaan sebagai berikut:

$$
\mathbf{A}=\left[\begin{array}{ccccccc}
34 & 33,1 & 34,8 & & 34,7 & 35 & 34,3 \\
32,3 & 34,4 & 35 & \ldots & 35,4 & 33,8 & 34,5 \\
34,9 & 35 & 35 & & 35,8 & 33,8 & 34,2 \\
& \vdots & & \ddots & & \vdots & \\
32,8 & 33,6 & 35,2 & & 35,5 & 34 & 34,8 \\
36 & 34,4 & 36,2 & \cdots & 36,4 & 35,6 & 34,3 \\
35,2 & 35,2 & 35,4 & & 36 & 34,4 & 34,6
\end{array}\right]
$$

Langkah pertama yang dilakukan dalam melakukan perhitungan Transformasi Fourier Cepat adalah mencari nilai dari $N$ dan $M$ sebagai berikut:

$$
\begin{aligned}
N & =120 \\
M & =\frac{N}{2} \\
& =60
\end{aligned}
$$

Persamaan Euler $e^{ \pm i a}=\cos a \pm i \sin a$ [2] dapat digunakan untuk mencari $W_{N}$ dan $W_{M}$ sehingga diperoleh sebagai berikut:

$$
\begin{aligned}
W_{N} & =W_{120} \\
& =0,99863-0,52335 i \\
W_{M} & =W_{60} \\
& =0,99452-0,10452 i
\end{aligned}
$$

Selanjutnya Persamaan (20) dan (21) disederhanakan dengan pemisalan variabel baru $E_{k}$ untuk fungsi genap dan $O_{k}$ untuk fungsi ganjil

$$
\begin{aligned}
& E_{k}=\sum_{n=0}^{M-1} f_{2 n} W_{M}^{n k} \\
& O_{k}=\sum_{n=0}^{M-1} f_{(2 n+1)} W_{M}^{n k}
\end{aligned}
$$

Persamaan (20) menjadi

Persamaan (21) menjadi

$$
F_{k}=E_{k}+W_{N}^{k} O_{k}
$$

$$
F_{k+M}=E_{k}-W_{N}^{k} O_{k}
$$

Selanjutnya dicari fungsi genap dan fungsi ganjil pada Transformasi Fourier Cepat, sehingga untuk fungsi genap diperoleh sebagai berikut:

$$
\mathbf{E}_{\mathbf{k}}=\left[\begin{array}{ccccccc}
W_{60}^{0} & W_{60}^{0} & W_{60}^{0} & & W_{60}^{0} & W_{60}^{0} & W_{60}^{0} \\
W_{60}^{0} & W_{60}^{1} & W_{60}^{2} & \cdots & W_{60}^{57} & W_{60}^{58} & W_{60}^{59} \\
W_{60}^{0} & W_{60}^{2} & W_{60}^{4} & & W_{60}^{104} & W_{60}^{106} & W_{60}^{108} \\
& \vdots & & \ddots & & \vdots \\
W_{60}^{0} & W_{60}^{57} & W_{60}^{114} & & W_{60}^{3249} & W_{60}^{3306} & W_{60}^{3363} \\
W_{60}^{0} & W_{60}^{58} & W_{60}^{116} & \cdots & W_{60}^{3306} & W_{60}^{3364} & W_{60}^{3422} \\
W_{60}^{0} & W_{60}^{59} & W_{60}^{118} & & W_{60}^{3363} & W_{60}^{3422} & W_{60}^{3481}
\end{array}\right]\left[\begin{array}{c}
f_{0} \\
f_{2} \\
f_{4} \\
\vdots \\
f_{114} \\
f_{116} \\
f_{118}
\end{array}\right]
$$




$$
=\left[\begin{array}{c}
2129,8 \\
-3,2064+3,825 i \\
-2,2764-0,83026 i \\
\vdots \\
-11,485-7,0488 i \\
-2,2764+0,83026 i \\
-3,2064-3,825 i
\end{array}\right]
$$

Sedangkan untuk fungsi ganjil diperoleh sebagai berikut:

$$
\begin{aligned}
\mathbf{0}_{\mathbf{k}} & =\left[\begin{array}{ccccccc}
W_{60}^{0} & W_{60}^{0} & W_{60}^{0} & & W_{60}^{0} & W_{60}^{0} & W_{60}^{0} \\
W_{60}^{0} & W_{60}^{1} & W_{60}^{2} & \cdots & W_{60}^{57} & W_{60}^{58} & W_{60}^{59} \\
W_{60}^{0} & W_{60}^{2} & W_{60}^{4} & & W_{60}^{104} & W_{60}^{106} & W_{60}^{108} \\
& \vdots & & \ddots & & \vdots & \\
W_{60}^{0} & W_{60}^{57} & W_{60}^{114} & & W_{60}^{3249} & W_{60}^{3306} & W_{60}^{3363} \\
W_{60}^{0} & W_{60}^{58} & W_{60}^{116} & \cdots & W_{60}^{3306} & W_{60}^{3364} & W_{60}^{3422} \\
W_{60}^{0} & W_{60}^{59} & W_{60}^{118} & & W_{60}^{3363} & W_{60}^{3422} & W_{60}^{3481}
\end{array}\right]\left[\begin{array}{c}
f_{1} \\
f_{3} \\
f_{5} \\
\vdots \\
f_{115} \\
f_{117} \\
f_{119}
\end{array}\right] \\
& =\left[\begin{array}{c}
2129,7 \\
0,39704+8,9088 i \\
0,67993+4,1398 i \\
\vdots \\
-6,2842-2,1378 i \\
0,67993-4,1398 i \\
0,39704-8,9088 i
\end{array}\right]
\end{aligned}
$$

Selanjutnya substitusikan nilai dari fungsi genap dan fungsi ganjil ke Persamaan (22) dan (23) sehingga diperoleh sebagai berikut:

$$
\begin{aligned}
\hat{f}_{0} & =E_{0}+W_{N}^{0} O_{0} \\
& =4259,5 \\
\hat{f}_{1} & =E_{1}+W_{N}^{1} O_{1} \\
& =-2,344+12,701 i \\
& \vdots \\
\hat{f}_{118} & =E_{58}-W_{N}^{58} O_{58} \\
\hat{f}_{119} & =E_{59}-W_{N}^{59} O_{59} \\
& =-2,344-12,701 i
\end{aligned}
$$

Hasil dari kebalikan frekuensi selanjutnya digunakan untuk mencari periode. Berikut gambar hasil periode suhu udara di Kota Pontianak dari tahun 2008 sampai dengan 2017.

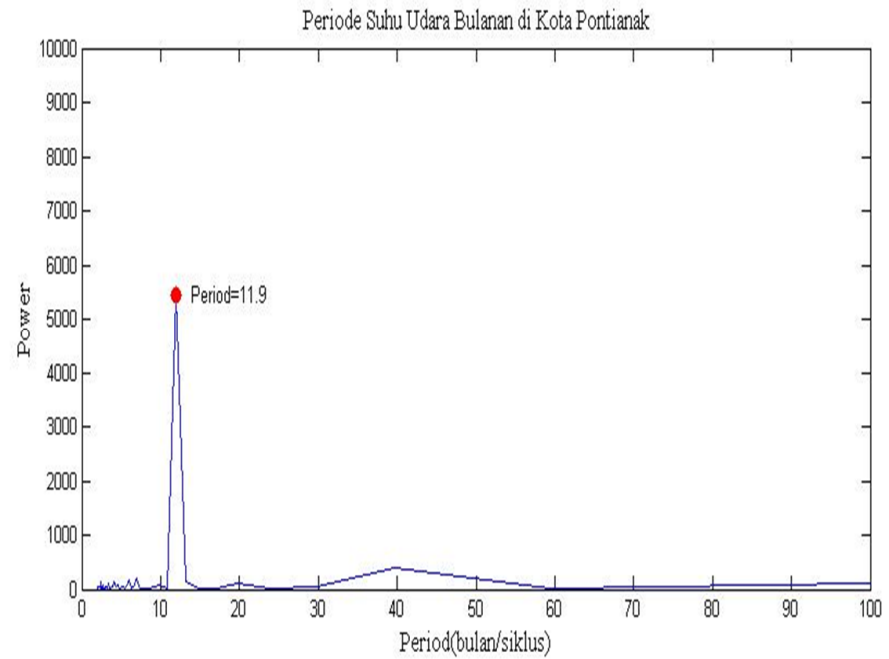

Gambar 1. Periode Suhu Udara di Kota Pontianak Tahun 2008-2017

Berdasarkan Gambar 1 diperoleh bahwa periode suhu udara di Kota Pontianak terletak pada rentang waktu 10 sampai 20 bulan. Sumbu $x$ yaitu menunjukkan waktu dan sumbu $y$ yaitu 
menunjukkan amplitudo (power) dari data suhu udara. Periode suhu udara yang diperoleh menggunakan Transformasi Fourier Cepat, dalam waktu 10 tahun dari tahun 2008 sampai dengan 2017 adalah $11,9 \approx 12$ bulan. Hasil penelitian tersebut menunjukkan bahwa kenaikan dan penurunan suhu udara berulang setiap 12 bulanan.

\section{APROKSIMASI DERET FOURIER PADA SUHU UDARA}

Berdasarkan Persamaan (1) Deret Fourier kontinu secara umum dapat dituliskan sebagai berikut:

$$
f(t)=a_{0}+\sum_{k=1}^{\infty}\left[a_{k} \cos (k \omega t)+b_{k} \sin (k \omega t)\right]
$$

dan berdasarkan Persamaan (2) sampai dengan (4) dapat diperoleh sebagai berikut:

$$
\begin{aligned}
& a_{0}=\frac{1}{T} \int_{t_{0}}^{t_{0}+T} f(t) d t \\
& a_{k}=\frac{2}{T} \int_{t_{0}}^{t_{0}+T} f(t) \cos (k \omega t) d t \\
& b_{k}=\frac{2}{T} \int_{t_{0}}^{t_{0}+T} f(t) \sin (k \omega t) d t
\end{aligned}
$$

Diasumsikan bahwa pada interval $\left[t_{0}, t_{0}+T\right]$ diketahui periode $\Delta T=\frac{T}{N}$ bahwa $f(t)$ adalah fungsi dengan waktu kontinu sedangkan $f(n \Delta T)$ adalah fungsi dengan data ke $n(n=1, \ldots, N)$. Selanjutnya $f(n \Delta T)$ dapat didekati dengan data diskrit sehingga diperoleh sebagai berikut:

$$
\begin{aligned}
a_{0} & =\frac{1}{T} \int_{t_{0}}^{t_{0}+T} f(t) d t \\
& =\frac{1}{N} \sum_{n=1}^{N} f(n \Delta T) \\
a_{k} & =\frac{2}{T} \int_{t_{0}}^{t_{0}+T} f(t) \cos (k \omega t) d t \\
& =\frac{2}{N} \sum_{n=1}^{N} f(n \Delta T) \cos \left(k \frac{2 \pi}{N} n\right) \\
b_{k} & =\frac{2}{T} \int_{t_{0}}^{t_{0}+T} f(t) \sin (k \omega t) d t \\
& =\frac{2}{N} \sum_{n=1}^{N} f(n \Delta T) \sin \left(k \frac{2 \pi}{N} n\right)
\end{aligned}
$$

Misalkan $\Delta T=1$, substitusikan ke Persamaan (1), (24), (25) dan (26) sehingga diperoleh sebagai berikut:

$$
\begin{aligned}
f(n \Delta T) & =f(n)=a_{0}+\sum_{k=1}^{\infty}\left(a_{k} \cos \left(k \frac{2 \pi}{N} n\right)+b_{k} \sin \left(k \frac{2 \pi}{N} n\right)\right) \\
a_{0} & =\frac{1}{N} \sum_{n=1}^{N} f(n) \\
a_{k} & =\frac{2}{N} \sum_{n=1}^{N} f(n) \cos \left(k \frac{2 \pi}{N} n\right) \\
b_{k} & =\frac{2}{N} \sum_{n=1}^{N} f(n) \sin \left(k \frac{2 \pi}{N} n\right)
\end{aligned}
$$

Fungsi $f(n)$ adalah fungsi waktu diskrit. Berdasarkan $\Delta T=\frac{T}{N}$ dan metode Transformasi Fourier Cepat pada Persamaan (22) dan (23) diperoleh periode suhu udara di Kota Pontianak yaitu 12 bulan, maka dapat diperoleh nilai $N=12$. Prediksi suhu udara di Kota Pontianak dapat diperoleh dari persamaan aproksimasi deret Fourier sebagai berikut:

$$
\hat{S}(t)=a_{0}+\sum_{k=1}^{L}\left(a_{k} \cos \left(k \frac{2 \pi}{12} t\right)+b_{k} \sin \left(k \frac{2 \pi}{12} t\right)\right)
$$

dan koefisien aproksimasi fourier

$$
\begin{aligned}
& a_{0}=\frac{1}{12} \sum_{t=1}^{12} S(t) \\
& a_{k}=\frac{2}{12} \sum_{t=1}^{12} S(t) \cos \left(k \frac{2 \pi}{12} t\right) \\
& b_{k}=\frac{2}{12} \sum_{t=1}^{12} S(t) \sin \left(k \frac{2 \pi}{12} t\right)
\end{aligned}
$$

\section{PREDIKSI SUHU UDARA}


Langkah awal yang dilakukan untuk memprediksi suhu udara yaitu mencari koefisien-koefisien Deret Fourier pada data suhu udara. Setelah mendapatkan koefisien- koefisien Deret Fourier kemudian disubstitusikan ke Persamaan (27) untuk mencari orde yang paling mendekati aproksimasi.

Data sampel suhu udara bulanan tahun 2008 adalah sebagai berikut:

$A=\left[\begin{array}{lllllll}34 & 33,1 & 34,8 & \cdots & 34,7 & 35 & 34,3\end{array}\right]$

Diketahui $N=12$ dan $S(t)$ adalah data suhu udara bulanan yang diperoleh dari Badan Meteorologi dan Geofisika Stasiun Meteorologi Maritim Pontianak Selanjutnya, dicari koefisien-koefisien aproksimasi Deret Fourier. Jadi, diperoleh koefisien Deret Fourier $a_{0}$ yaitu 35,058 dan koefisienkoefisien Deret Fourier lain dapat dibentuk tabel sebagai berikut:

Tabel 1. Nilai dari Koefisien-Koefisien Deret Fourier

\begin{tabular}{cccc}
\hline Koefisien $a_{k}$ & Nilai Koefisien $a_{k}$ & Koefisien $b_{k}$ & Nilai Koefisien $b_{k}$ \\
\hline$a_{1}$ & $-1,034$ & $b_{1}$ & $-0,538$ \\
$a_{2}$ & 0,275 & $b_{2}$ & $-0,361$ \\
$a_{3}$ & 0,100 & $b_{3}$ & 0,117 \\
$a_{4}$ & 0,192 & $b_{4}$ & $-0,130$ \\
$a_{5}$ & 0,034 & $b_{5}$ & 0,155 \\
$a_{6}$ & $-0,650$ & $b_{6}$ & 0.000 \\
$a_{7}$ & 0,034 & $b_{7}$ & $-0,155$ \\
$a_{8}$ & 0,192 & $b_{8}$ & 0,130 \\
$a_{9}$ & 0,100 & $b_{9}$ & $-0,117$ \\
$a_{10}$ & 0,275 & $b_{10}$ & 0,361 \\
$a_{11}$ & $-1,034$ & $b_{11}$ & 0,538 \\
$a_{12}$ & 70,117 & $b_{12}$ & 0.000 \\
\hline
\end{tabular}

Tabel 1 merupakan tabel yang berisikan nilai dari koefisien-koefisien pada Deret Fourier dengan nilai terbesar yaitu $a_{0}=35,058$ dan nilai terkecil yaitu $b_{6}=0$. Setelah mendapatkan koefisienkofisien Deret Fourier maka selanjutnya koefisien tersebut akan disubstitusikan ke Persamaan (27). Berdasarkan hasil prediksi suhu udara pada setiap tahunnya diperoleh nilai MAPE dan MSE yang paling mendekati. Hasil aproksimasi Deret Fourier yang paling mendekati untuk data sampel suhu udara tahun 2008 yaitu berorde enam dan tujuh $(L=6$ dan $L=7)$ sedangkan untuk tahun 2009 sampai dengan 2017 yaitu berorde lima dan enam $(L=5$ dan $L=6)$. Hasil prediksi suhu udara berorde sama dengan kata lain berorde enam selanjutnya digunakan untuk memprediksi suhu udara tahun 2018.

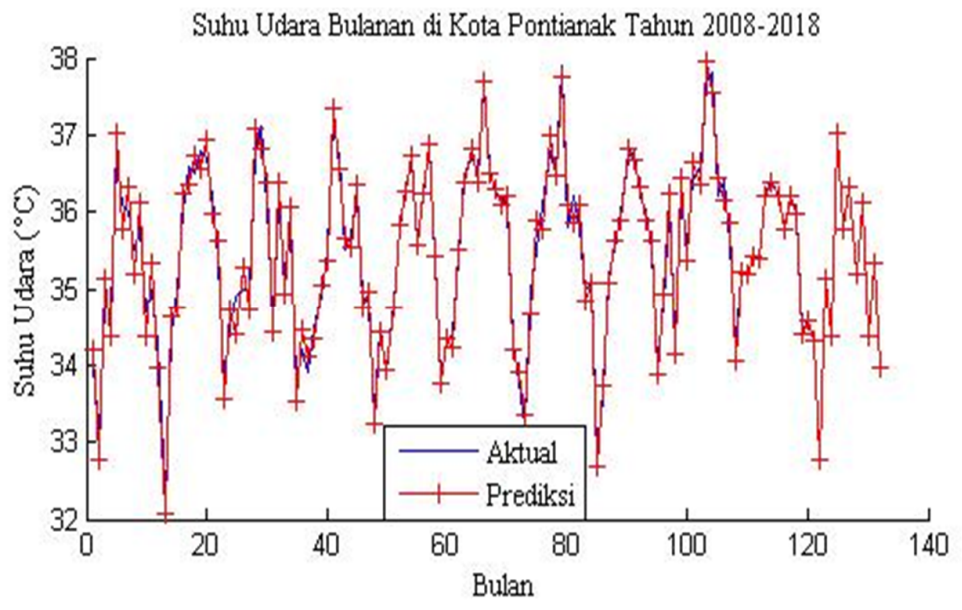


Gambar 2. Perbandingan Data Suhu Udara dengan Data Prediksi Aproksimasi Deret Fourier Tahun $2008-2018$

Gambar 2 merupakan prediksi suhu udara di Kota Pontianak pada tahun 2008 sampai dengan 2018 untuk $L=6$. Hasil prediksi suhu udara yang diperoleh pada tahun 2018 adalah suhu udara $32,775^{\circ} \mathrm{C}$ hingga $37,025^{\circ} \mathrm{C}$. Suhu udara mencapai $37,025^{\circ} \mathrm{C}$ terjadi di bulan Mei. Berdasarkan Peraturan Kepala Badan Meteorologi, Klimatologi dan Geofisika Nomor Keputusan 009 Tahun 2010, suhu udara ekstrim adalah kondisi suhu udara yang mencapai $3^{\circ} \mathrm{C}$ (tiga derajat celcius) atau lebih di atas nilai normal setempat. Berdasarkan data suhu udara bulanan di Kota Pontianak dari tahun 2008 sampai dengan 2017 diperoleh nilai suhu udara normal atau suhu normal yaitu sebesar $35,5^{\circ} \mathrm{C}$. Berdasarkan uraian tersebut, maka hasil prediksi menunjukkan bahwa suhu udara di Kota Pontianak tidak ekstrim atau masih dalam kondisi normal.

\section{PENUTUP}

Adapun kesimpulan yang diperoleh pada penelitian ini adalah sebagai berikut:

1. Periode suhu udara di Kota Pontianak yang diperoleh dari tahun 2008 sampai tahun 2017 dengan menggunakan metode Transformasi Fourier Cepat adalah 12 bulan. Hasil penelitian menunjukkan bahwa kenaikan dan penurunan suhu udara berulang setiap 12 bulanan.

2. Prediksi suhu udara di Kota Pontianak yang diperoleh dari tahun 2008 sampai 2017 menggunakan aproksimasi Deret Fourier berorde enam. Hasil prediksi suhu udara di Kota Pontianak pada tahun 2018 adalah suhu udara maksimum mencapai $37,025^{\circ} \mathrm{C}$. Berdasarkan Peraturan Kepala Badan Meteorologi, Klimatologi dan Geofisika Nomor Keputusan 009 Tahun 2010 mengenai definisi suhu udara ekstrim, maka hasil prediksi tersebut menunjukkan bahwa suhu udara di Kota Pontianak tidak ekstrim atau masih dalam kondisi normal.

\section{DAFTAR PUSTAKA}

[1]. Christienova SI, Wahyu EP, Darmawan G. Perbandingan Model Peramalan Singular Spectrum Analysis (SSA) dan Fourier Series Analysis (FSA) pada Data Suhu Udara di Surabaya. Berkala MIPA. 2018; 1:94-106.

[2]. Zong-chang Y. Fourier Analysis-based Air Temperature Movement Analysis and Forecast. IET Signal Process. 2013; 7:14-24.

[3]. Chapra SC, Canale RP. Numerical Method for Engineers Ed ke-7. New York: Mc Graw Hill Eduction; 2015.

[4]. Kreyzig E. Advanced Engineering Mathematics Ed ke-9. United States: John Wiley \& Sons Inc; 2006.

[5]. Suminto H. Metode dan Aplikasi Peramalan Jilid I Ed ke-2. [Makridakis S, Wheelwright SC, McGee]. Jakarta: Binarupa Aksara; 1999.

[6]. Halimi R, Anggraeni W, Tyasnurita R. Pembuatan Aplikasi Peramalan Jumlah Permintaan Produk dengan Metode Time Series Exponential Smoothing Holts Winter di PT. Telekomunikasi Indonesia Tbk. Jurnal Teknik Pomits, 2013; 1: 1-6.

$\begin{array}{ll}\text { MAULYDIANA SEPTIANI } & \begin{array}{c}\text { : Jurusan Matematika FMIPA Untan, Pontianak, } \\ \text { maulydianas@ student.untan.ac.id } \\ \text { : Jurusan Matematika FMIPA Untan, Pontianak, } \\ \text { helmi132205@yahoo.co.id } \\ \text { : Jurusan Matematika FMIPA Untan, Pontianak, } \\ \text { dhye_dhoank@yahoo.uk }\end{array} \\ \text { YUDHI } & \end{array}$

